\title{
Design and Development of Oral Reconstituable System of Dry Syrup Containing Ciprofloxacin
}

\author{
Doifode $\mathrm{RA}^{1^{*}}$, Ghogare JD ${ }^{1}$, Pratapwar $\mathrm{AS}^{2}$, Panchal PP ${ }^{1}$, Jadhao UT ${ }^{1}$
}

${ }^{1}$ Department of Pharmaceutics SDMVM's SVP College of pharmacy Hatta, Dist. Hingoli, Maharashtra, India

${ }^{2}$ Department of Pharmaceutics SNIOP, Pusad Dist- Yavatmal MS, Maharashtra, India

DOI: $\underline{10.36347 / \text { sajp.2021.v10i02.001 }}$

| Received: 08.02.2021 | Accepted: 22.02.2021 | Published: 27.02.2021

*Corresponding author: Rakhi Ashok Doifode

Abstract

Original Research Article

Ciprofloxacin is a broad spectrum antibiotic, active against both gram positive and gram negative bacteria. This drug is a highly bitter in taste. The present investigation was undertaken with an overall objective of studying the drug resin complexation (DRC) to mask the bitter taste of the drugs. Indion 234 and drug, ciprofloxacin were selected for the study of feasibility of employing drug resin complexation for masking the bitter taste of drug. FTIR studies indicated that there would be a possibility of chemical modification in the DRC without any changes in basic nucleus of the drug. Taste evolution of ion exchange in healthy human volunteers confirmed that the taste of Ciprofloxacin was successfully masked by ion exchange with (DRC) 1:3 ratios. Prepared batches of dry syrup was evaluated for drug content, taste of the dry syrup after reconstitution, $\mathrm{pH}$ of the syrup, sedimentation volume, specific gravity and dissolution characteristics. The dissolution of the drug from the reconstituted syrup follows first order kinetics. Among all the formulations F8 was found to be better formulation ciprofloxacin because of high dissolution rate and taste masking.

Keywords: Dry Syrup, Ciprofloxacin, and Indion 234, resinate complex, Taste masking.

Copyright $\odot 2021$ The Author(s): This is an open-access article distributed under the terms of the Creative Commons Attribution 4.0 International License (CC BY-NC 4.0) which permits unrestricted use, distribution, and reproduction in any medium for non-commercial use provided the original author and source are credited.

\section{INTRODUCTION}

A number of patients, especially Pediatric and Geriatric patients have difficulty in swallowing solid dosage forms hence liquid dosage forms are needed. So drugs which are slightly soluble in water hence formulation of a suspension will be most suitable but product may be physically and chemically stable. In the present work, attention is paid to develop a reconstitutable suspension form as dry syrup. Dry Syrups are commercial dry mixtures that require the addition of water at the time of dispensing. The dry syrup is prepared commercially using drug colorants, flavours, sweeteners, stabilizing agents and preserving agents that may be preparations are available as dry powder mixtures or granules that are intended to be suspended in water or some other vehicle prior to oral administration. Most of the drugs prepared as a dry suspension for oral suspension are antibiotics. The dry mix of sweeteners, stabilizing agents, suspending agents and preserving agents that may be taken as a suspension in a glass containing prescribed amount of ingestible liquid, constitution in a liquid is stable for 24 hours after preparation, it is recommended that the suspension should be consumed immediately after preparation [13].

The most common reason for the formulation of Suspensions for reconstitution is inadequate chemical stability of the drug in an aqueous vehicle. In such cases, dissolution of even suspension of the drug results in a very short shelf life. For example, reconstituted suspensions of penicillin have a maximum shelf life of 14 days. The manufactured dry mixture, however, has a shelf life of at least 2 years. Another reason for the formulating Suspensions for Reconstitution is to avoid the physical stability problems often encountered in conventional suspensions. These problems include possible increased drug solubility due to $\mathrm{pH}$ changes from chemical degradation, incompatibility of ingredients, viscosity changes, conversion of polymorphic form and Crystal growth and caking. Formulation for Reconstitution reduces the weight of the final product because the aqueous vehicle is absent and consequently, transportation expenses may be reduced. The dry mixture may be shipped without regard to the seasonal temperatures because it's physical 
stability is less susceptible to temperature extremes as compared with conventional suspensions.

Based on complexation of drugs with ion exchange resins. Ion exchange resins are water insoluble, cross linked high molecular weight polyelectrolytes containing salt forming groups in repeating position on the Polymer chain which exchange their mobile ion of equal charge with the drug molecule. As taste perception of bitter drugs is experienced in the mouth at taste buds, complex drugs resinate does not release drug in mouth due of scarcity of exchangeable ions (at $\mathrm{pH}$ 6.7) in the saliva and when complex comes in contact with GIT fluids (at acidic $\mathrm{pH}$ ), complex is broken down quickly and drug is release. Resins being polyelectrolyte have extensive binding sites leading to very high drug loading ability. Ion exchange resins have received considerable attention because of their versatile properties as drug delivery vehicles, chemically inert and free from local and systematic side effect possessstyrene Divinylbenzene long term safety even while the ingesting large doses and also compatible with all conventional solid, semisolid [4].

\section{METHODS AND MATERIALS Material}

Ciproflaxin was obtained as kind gift sample from Healthy life Pharma Pvt Ltd Mumbai India Indion 234 purchased from Ion exchange India LTD, Mumbai; Acacia \& Tragacanth was purchased from Thomas baker, Mumbai India. All other materials used of analytical grades.

\section{Methods \\ Preformulation Studies \\ Threshold bitterness concentration of Ciprofloxacin Six healthy human volunteers held $10 \mathrm{ml}$ solution of Ciprofloxacin of concentration 0 , $50,75,100,150,200 \mathrm{~g} / \mathrm{ml}$ in Phosphate buffer pH 6.8 respectively, in their mouth for $30 \mathrm{sec}$ and rinsed their mouth with $50 \mathrm{ml}$ of phosphate buffer $\mathrm{pH} \mathrm{6.8.} \mathrm{The}$ bitterness threshold concentration was judged by considering opinion of volunteers and statics was applied for the same.}

\section{Taste Evaluation}

The bitterness evaluation taste was performed with human volunteers according to previous described method. Test was carried out on a trained test panel of 6 human volunteers ( 3 males and 3 females, with a mean age of 25 years), from who informed consent was first obtained. The volunteers rinsed their mouths thoroughly before and after the tasting. Each sample was held in the volunteer's mouth for 30 s and then expectorated, and the taste was evaluated and assigned the numerical value according to the following scale: 0-Tasteless, 1Slight Bitter, 2-Moderate bitter, 3-Strong bitter. The lower score indicated a great masking effect $[5,6]$.

\section{Selection of Method for Taste Masking of} Ciprofloxacin

Resin can be selected on the nature of drug and requirement of formulation. Depending on the basis of acidic and basic nature of the drug, cation and anion exchange resin can be used. In the present work weak cation exchange resin Indion 234 was selected based on their ion exchange capacity and used for the taste masking of Ciprofloxacin.

\section{Optimizing drug loading [7]}

Accurate weighted ciprofloxacin $(100 \mathrm{mg})$ was added to $130 \mathrm{mg}$ of activated resin and slurred in $25 \mathrm{ml}$ of deionized water. Six batches with a stirring time of 5, 10, 15, 20, 30 and 250 minutes were processed. Amount of bound drug at the end was estimated at $279 \mathrm{~nm}$.

\section{Characterization of Ion exchange resins}

Indion 234 was characterized using Infrared spectrum. IR spectrum of Indion 234 is shown in fig. 9.3

\section{Particle size analysis $[8,9]$}

The particle size of the resin Indion 234 was measured using digital microscope, catcam microscope eyepiece digital camera (DCM35). The resin powder was placed on a glass slide and analyzed using microscopy. The average diameter of the resin particles was determined.

\section{Water absorption time of resin [10]}

Water absorption of resins were measured by contacting $500 \mathrm{mg}$ of Indion 234 with $1 \mathrm{ml}$ of water and measuring the time in secs required for the water to be absorbed.

\section{Effect of swelling of resin on drug loading}

Separate batches of activated Indion 234 (200 $\mathrm{mg}$ ) were soaked in $25 \mathrm{ml}$ of deionized water contained in a breaker for 10, 30, 60 and 120 minutes respectively. The complexation in batch process was performed and the loading efficiency with resin swollen for different times was determined.

\section{Purification of resin [11]}

Indion 234 was purified by washing with distilled water. The wet resin activated by $0.1 \mathrm{M}$ HCL $300 \mathrm{ml}$ followed by washing with distilled water. The resin was then dried in vacuum oven at $60^{\circ} \mathrm{C}$ till the moisture content came below $5 \%$ which was checked by Karl Fisher Titrator. The purified resin was stored in an air tight glass vial.

\section{Preparation of drug resin complex [12]}

Ciprofloxacin was mixed with Indion 234 in the drug resin ratio of $1: 1,1: 2,1: 3$ and $1: 4,200 \mathrm{ml}$ of distilled water was added to the mixtures and stirred for 5 hours with magnetic stirrer to allow complete complexation of drug with resin. The drug resin complex so obtained was filtered by vacuum filtration 
Doifode RA et al., Sch Acad J Pharm, Feb, 2021; 10(2): 28-35

and the residue was washed with distilled water. The prepared resinate was dried in vacuum oven at $60^{\circ} \mathrm{C}$ till the moisture content was below $5 \%$.

\section{Evaluation of resinate:[13]}

\section{Drug content and percentage bound drug:}

The DRC equivalent to $100 \mathrm{mg}$ was dissolved in $100 \mathrm{ml}$ of $0.1 \mathrm{~N} \mathrm{HCL}$ and stirred 2 hour, till the entire drug leached out and then the solution was filtered through a Whatman filter paper. Further diluted to volume with $0.1 \mathrm{~N} \mathrm{HCL}$ and the drug content was determined spectrophotometrically at $279 \mathrm{~nm}$ using $0.1 \mathrm{~N}$ HCL as blank. Percentage drug bound, defined as total amount of drug in complex form divided by initial weight of drug added to resin slurry, was then calculated from percentage assay and total amount of complex obtained.

\section{Formulation of dry syrup using drug-resin complex}

\section{Selection of Excipients}

A) Suspending agents: Suspending agents suitable for use in suspensions for reconstitutation acacia, tragacanth, xanthan gum, povidone, carboxymethylcellulose sodium, lots careageenans, microcrystalline cellulose with CMC, propylene glycol alginate, silicone dioxide, colloidal, suspending agents should be easily dispersed by vigorous hand shaking during reconstitution. Combination of microcrystalline cellulose and sodium CMC is a common suspending agent.

B) Natural gums: Anionic and include exudates of trees and extracts from seaweed e.g.Carrageenans produce thixotropic dispersions. Acacia and tragacanth have been used as suspending agents for many years. Variation in colour, viscosity, gel strength and hydration rate.Common suspending agent in suspensions for reconstitutation. Produced by microbial fermentation, good batch to batch uniformity and few microbial problems. Required concentrations for rapid dispersion during reconstitution must be determined for each suspending agent.

C) Sweeteners: Sweeteners can mask the unfavorable taste and enhance patient acceptance in the paediatric population that uses this product. Any increased viscosity as a result of the sweeteners aids suspension of the drug particles. Sucrose can perform both above functions of sweetener and suspending agent and serve as a diluent in the dry mixture. Others include mannitol, dextrose, aspertame, saccharin sodium.

D) Wetting agents: Drugs in suspension are hydrophobic, repel water and are not easily wetted. Surfactants are commonly used to aid in the dispersion of hydrophobic drugs. Excess wetting agent can produce foaming and impart an unpleasant taste. Polysorbate 80 is a common wetting agent. Nonionic and is chemically compatible with both cationic and anionic excipients and drugs. Used in concentrations < $0.1 \%$. Another common wetting agent is sodium lauryl sulfate. Anionic and may be incompatible with cationic drugs.

The oral reconstitutable suspension of Ciprofloxacin was prepared from the optimized DRC (drug resin ratio 1:3). The formula is presented in table 12. All the ingredients for suspension were passed through mesh no. 40 to make uniform particle size dispersion. The DRC equivalent to $250 \mathrm{mg}$ was mixed with the excipients. The prepared suspension was evaluated for before and after reconstitution parameters.

Table-1: Formulation of dry syrup using drug resin complex

\begin{tabular}{|l|l|l|l|l|l|l|l|l|}
\hline $\begin{array}{l}\text { INGREDIENTS } \\
(\text { Mg) }\end{array}$ & F1 & F2 & F3 & F4 & F5 & F6 & F7 & F8 \\
\hline Ciprofloxacin & 250 & - & - & - & - & - & - & - \\
\hline DRC equivalent & - & 250 & 250 & 250 & 250 & 250 & 250 & 250 \\
\hline Acacia & 3 & 1.5 & - & - & 3 & 1.5 & - & - \\
\hline Tragacanth & 1.5 & 0.75 & 1.5 & 0.75 & 1.5 & 0.75 & 1.5 & 0.75 \\
\hline Sodium CMC & - & - & 1.8 & 0.9 & - & - & 1.8 & 0.9 \\
\hline Mannitol & 1.5 & 1.5 & 1.5 & 1.5 & 1.5 & - & 1.5 & 1.5 \\
\hline Mag. Stearate & 0.3 & 0.3 & 0.3 & 0.3 & 0.3 & 1.5 & 0.3 & 0.3 \\
\hline Sod. Benzoate & 0.06 & 0.06 & 0.06 & 0.06 & 0.06 & 0.3 & 0.06 & 0.06 \\
\hline Sucrose & 13.74 & 13.74 & 14.94 & 16.59 & 14.04 & 0.06 & 15.24 & 16.89 \\
\hline Total & $\mathbf{2 7 1}$ & $\mathbf{2 7 1}$ & $\mathbf{2 7 1}$ & $\mathbf{2 7 1}$ & $\mathbf{2 7 1}$ & $\mathbf{2 7 1}$ & $\mathbf{2 7 1}$ & $\mathbf{2 7 1}$ \\
\hline
\end{tabular}

\section{Evaluation of Taste Masked Oral Reconstitutable System}

\section{Micromeritics studies}

Bulk density and tapped density were determined using a bulk density apparatus. Angle of repose, compressibility index and Hausner ratio were evaluated as per methods described in USP 30-NF25. In the recent years compressibility index and the closely related Hausner ratio have become the simple, fast and popular methods of predicting powder flow characteristics.

\section{Rheological behavior}

The theological behavior of the reconstituted suspensions is determined using Brookfield viscometer (Model--RVT). 


\section{Sedimentation behavior [14]}

\section{Redispersibility}

The redispersibility is determined by studying the number of strokes to redisperse the formed sediment at the end of 7 days of storage of the formulations (not more than 100 strokes=Redispersibility).

\section{Sedimentation Volume Ratio (SVR)}

During the seventh day study sedimentation volume $(\mathrm{F})$ and degree of flocculation (Beta)

\section{Liquid flow rate}

Pipette our $10 \mathrm{ml}$ of the dry syrup sample using $10 \mathrm{ml}$ pipette. Now release the sample solution from the pipette and start the stopwatch. The time required for each suspension sample to flow through a $10 \mathrm{ml}$ pipette was determined and the apparent viscosity (. in mls-1) was calculated using the equation:

Flow rate $=$ Volume of Pipette $(\mathrm{ml}) /$ Flow time $(\mathrm{s})$

\section{Drug content}

$1 \mathrm{ml}$ of the suspension $(25 \mathrm{mg})$ was pipette into $100 \mathrm{ml}$ volumetric flask. $50 \mathrm{ml}$ of $0.1 \mathrm{~N} \mathrm{HCL}$ was added to this and mixed well for $15 \mathrm{~min}$ and volume was made up to $100 \mathrm{ml}$ by adding sufficient $0.1 \mathrm{HCL}$. The solution was analyzed at $279 \mathrm{~nm}$ for Ciprofloxacin.

\section{In vitro drug release}

The in vitro release profile of reconstituted dry syrup formulation was obtained by using USP type 11 dissolution apparatus. $10 \mathrm{ml}$ of reconstituted syrup equivalent to about $250 \mathrm{mg}$ of Ciprofloxacin was accurately pippeted out and put into $900 \mathrm{ml}$ of $0.1 \mathrm{~N}$ $\mathrm{HCL}\left(37^{\circ}+-0.5^{\circ} \mathrm{C}\right)$ and stirred at $100 \mathrm{rpm}$. Aliquots were taken at predetermined intervals and analyzed by UV-Visible spectrophotometer at $279 \mathrm{~nm}$ for Ciprofloxacin
Particle size [15]

The oral reconstitutable suspension is evaluated, the average particle size of the formulation is examined using standard microscopy method average and standard deviations of 100 particles are estimated.

\section{Stability study [16-19]}

The reconstitutable suspension is stored in air tight amber colored glass bottles for 36 days at $45^{\circ} \mathrm{C}$ and then reconstituted with distilled water to make up the volume to $30 \mathrm{ml}$ with gentle shaking. The reconstituted suspensions stored at various temperatures are evaluated after reconstitution and after 7 th and 15 th day of reconstitution.

\section{RESULTS AND DISCUSSION \\ Particle size analysis}

Particle size of resin affects the hydrating and swelling properties of resins and hence the drug release properties. The particle size of Indion 234 was found to be $56.33+-1.52$ micrometer which was in confirmation with the reported size, less than 150 micrometer. This size range has been reported to be applicable for taste masking property.

\section{Water absorption time of resin}

Water absorption time was measured by contacting 500mg of Indion 234 with $2 \mathrm{ml}$ of water and measuring the time in seconds for the water to be absorbed. Ion exchange resins are highly porous materials and even though they are water insoluble, they are capable of hydration by absorbing large amounts of water.

\section{Effect of swelling of resin on drug loading}

The effect of resin swelling on amount of drug loading was determined. The swelling time was optimized by carrying out loading of Ciprofloxacin in five different batches separately, where Indion 234 was allowed to swell for 10, 30, 60 and 120min.

Table-2: Effect of Indion 234 swelling on drug loading

\begin{tabular}{|l|l|l|}
\hline Sr no. & State of Indion 234 & Percent Drug Loading \\
\hline 1 & Unswollen resin & $77.22 \pm 0.51$ \\
\hline 2 & 10 min swelling & $85.76 \pm 0.47$ \\
\hline 3 & 30 min swelling & $96.98 \pm 0.72$ \\
\hline 4 & 60 min swelling & $97.17 \pm 0.39$ \\
\hline 5 & 120 min swelling & $97.54 \pm 0.78$ \\
\hline
\end{tabular}

\section{Determination of Threshold Bitterness \\ Concentration Ciprofloxacin}

Threshold bitterness concentration is the minimum concentration at which bitterness starts to appear and continues to provoke after 30s. Most of the volunteers rated $20 \mu \mathrm{g} / \mathrm{ml}$ as the threshold bitterness concentration for Ciprofloxacin as shown in Table no 2. It was found that the taste masked form of the drug should not release more than or equal to $30 \mu \mathrm{g} / \mathrm{ml}$ of the drug in mouth within 2 minutes for satisfactory taste masking. 
Table-3: Bitterness evaluation by taste Pannel method:

\begin{tabular}{|l|l|l|l|l|l|l|l|}
\hline \multicolumn{2}{|l|}{ Type of product } & \multicolumn{7}{|c|}{ I } & II & III & IV & V & VI \\
\hline Ciproflaxin Pure Drug & $30 \mathrm{~s}$ & $4+$ & $4+$ & $4+$ & $4+$ & $4+$ & $4+$ \\
\hline DRC(1.1) & $30 \mathrm{~s}$ & 1 & 1 & 1 & 1 & 1 & 1 \\
\hline $\mathrm{DRC}(1.2)$ & $30 \mathrm{~s}$ & 1 & 0 & 1 & 0 & 1 & 0 \\
\hline $\mathrm{DRC}(1.3)$ & $30 \mathrm{~s}$ & 0 & 0 & 0 & 1 & 0 & 0 \\
\hline DRC(1.4) & $30 \mathrm{~s}$ & 0 & 0 & 1 & 0 & 0 & 0 \\
\hline
\end{tabular}

$0=$ No bitterness, $1=$ Threshold bitterness, $2=$ Bitter, $3=$ Moderate bitter, $4=$ Strong bitter

\section{Optimizing drug loading of stirring time}

The ion exchange process is an equilibrium reaction and the rate, where the exchange between the counter ions in the resin and ions in the solution occurs in stoichiometry. Therefore, it was essential to know the time required for equilibration. For the purpose drug resin complex was prepared for different time periods, where the complex was on a magnetic stirrer and the percent drug loading obtained at different time was calculated. Maximum drug loading occurs in $30 \mathrm{~min}$ stirring.

Table-4: Effect of stirring time on drug loading

\begin{tabular}{|l|l|l|}
\hline Sr no. & Stirring Time(in min) & Percent Drug Loading \\
\hline 1 & 5 & $50.20 \%$ \\
\hline 2 & 10 & $56.25 \%$ \\
\hline 3 & 15 & $71.27 \%$ \\
\hline 4 & 20 & $93.53 \%$ \\
\hline 5 & 30 & $95.50 \%$ \\
\hline 6 & 240 & $95.63 \%$ \\
\hline
\end{tabular}

\section{Drug content and \% drug bound in complex}

When DRC of various batches of 1:1, 1:2, 1:3, 1:4 were prepared using optimized parameters for drug loading, the percent bound drug were found to be $92.34 \%, 96.26 \%, 96.50 \%$ and $97.26 \%$ respectively. And drug content was $45 \%, 44 \%, 43 \%$ and $43 \% \mathrm{w} / \mathrm{w}$ respectively. An increase in amount of resin does not give correspondingly high increment in drug content. In case of ratios $1: 1$ and 1:2 drug bound was less than $1: 3$ and 1:4 as shown by the result of one way of ANOVA where the $\mathrm{p}$ value $(\mathrm{p}<0.05)$ indicated significant difference. The ratio of 1:3 was selected as the optimum ratio because increasing the resin amount for an insignificant increase in drug loading is not an economically viable approach.

Table-5: Drug content and \% drug bound in complex

\begin{tabular}{|l|l|l|l|}
\hline Sr no. & Drug resin complex & \% drug content & Percentage bound drug \\
\hline 1 & DRC $(1: 1)$ & $45 \%$ & $92.34 \% \pm 0.98 \%$ \\
\hline 2 & DRC $(1: 2)$ & $44 \%$ & $96.26 \% \pm 0.88 \%$ \\
\hline 3 & DRC $(1: 3)$ & $43 \%$ & $96.50 \% \pm 0.10 \%$ \\
\hline 4 & DRC $(1: 4)$ & $43 \%$ & $97.34 \% \pm 0.88 \%$ \\
\hline
\end{tabular}

\section{Micrometric studies of resinate complex}

Formulation F1 and the taste masked powder mixture of all the formulations F2-F8 were tested by various studies including bulk density (ranging from
$0.48-0.50 \mathrm{gm} / \mathrm{ml}$ ), tap density (ranging from 0.5610 $5806 \mathrm{gm} / \mathrm{ml}$ ) and angle of repose (ranging from $26.23^{\circ} \mathrm{C}$ to $28.10^{\circ} \mathrm{C}$ ). All the results showed good flow properties.

Table-6: Evaluation of taste masked oral reconstitutable suspension

\begin{tabular}{|c|c|c|c|c|c|c|c|}
\hline \multirow[t]{2}{*}{ Formulation } & \multirow{2}{*}{$\begin{array}{l}\text { Average } \\
\text { particle size }\end{array}$} & \multirow{2}{*}{$\begin{array}{l}\text { Viscosity } \\
\text { (cps) }\end{array}$} & \multirow{2}{*}{$\begin{array}{l}\text { Flowrate } \\
(\mathbf{m l} / \mathbf{s})\end{array}$} & \multirow[t]{2}{*}{ pH } & \multirow{2}{*}{$\begin{array}{l}\text { Redispersibility } \\
\text { (no of strokes) }\end{array}$} & \multicolumn{2}{|c|}{ Sedimentation Volume } \\
\hline & & & & & & $\mathbf{F}$ & $\beta$ \\
\hline F1 & 20.5 & $600 \pm 0.12$ & 0.55 & 5.3 & 10 & 0.1 & 1 \\
\hline F2 & 22.5 & $553 \pm 0.11$ & 0.52 & 5.2 & 10 & 0.2 & 1 \\
\hline F3 & 21.8 & $502 \pm 0.10$ & 0.52 & 5.3 & 10 & 0.2 & 1 \\
\hline F4 & 22.3 & $412 \pm 0.15$ & 0.55 & 5.2 & 10 & 0.1 & 1 \\
\hline F5 & 21.3 & $500 \pm 0.24$ & 0.52 & 5.3 & 10 & 0.2 & 1 \\
\hline F6 & 23.0 & $400 \pm 0.12$ & 0.55 & 5.2 & 10 & 0.1 & 1 \\
\hline F7 & 21.1 & $600 \pm 0.02$ & 0.55 & 5.3 & 10 & 0.2 & 1 \\
\hline F8 & 22.3 & $505 \pm 0.14$ & 0.55 & 5.3 & 10 & 0.2 & 1 \\
\hline
\end{tabular}




\section{In vitro drug release}

In vitro release profile of DRC shows drug release of $95 \%$ within 35 min in $0.1 \mathrm{~N}$ HCL. Indion 234 is a weak cationic resin and has high affinity for $\mathrm{H}+$ ions. So, in acidic environment, it readily loses the absorbed drug species hence drug release is observed at faster rate. In vitro drug release in average salivary $\mathrm{pH}$ of 6.8 was $4.86 \%$ within 60 seconds, 5.46 within 120 seconds and $11.17 \%$ within 180 seconds. The presence of exchangeable ions of ionizable electrolytes in the salivary fluid may be responsible for this release. The DRC is stable in salivary $\mathrm{pH}$ for a period of administration. The amount released is insufficient to impart bitter taste while the formulation passes through the mouth to further parts of the gastrointestinal tract.

Table-7: Cumulative percentage of drug released

\begin{tabular}{|l|l|l|l|l|l|l|l|l|}
\hline Times in min. & F1 & F2 & F3 & F4 & F5 & F6 & F7 & F8 \\
\hline $\mathbf{5}$ & 27.00 & 22.00 & 22.02 & 21.00 & 20.02 & 20.00 & 21.00 & 20.02 \\
\hline $\mathbf{1 0}$ & 35.00 & 33.01 & 35.03 & 28.10 & 32.09 & 30.20 & 32.00 & 28.00 \\
\hline $\mathbf{1 5}$ & 50.05 & 44.03 & 47.05 & 45.03 & 46.05 & 48.05 & 43.05 & 48.03 \\
\hline $\mathbf{2 0}$ & 57.67 & 54.61 & 57.63 & 53.64 & 54.63 & 55.67 & 54.67 & 55.67 \\
\hline $\mathbf{2 5}$ & 69.43 & 64.42 & 66.45 & 65.45 & 63.45 & 65.45 & 66.45 & 63.45 \\
\hline $\mathbf{3 0}$ & 80.84 & 79.84 & 80.84 & 78.84 & 80.84 & 79.84 & 80.82 & 80.80 \\
\hline $\mathbf{3 5}$ & 99.79 & 93.42 & 93.42 & 92.40 & 92.42 & 92.41 & 95.43 & 96.82 \\
\hline
\end{tabular}

\section{Characterization of Ion exchange resins}

Ciprofloxacin was identified by FT-IR study and the prominent peaks are obtained at $3335.394 \mathrm{~cm}-1$
(O-H stretching), $1700.643 \mathrm{~cm}-1 \quad(\mathrm{C}=\mathrm{O}$ stretching), $1023.647 \mathrm{~cm}-1$ (C-F stretching).

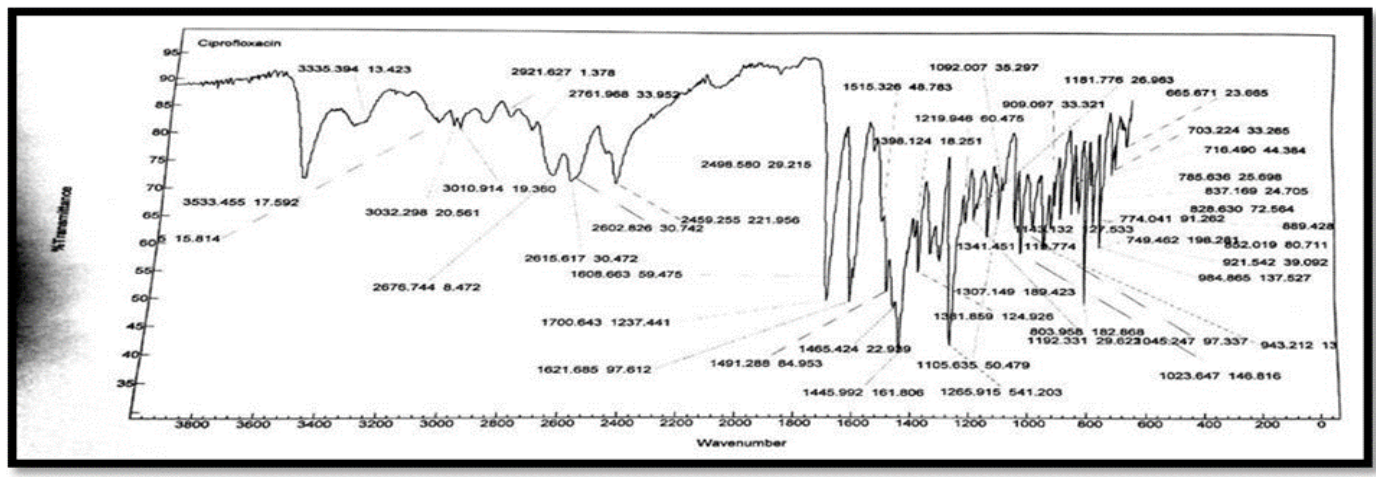

Fig-1: IR Spectrum of pure drug ciprofloxacin

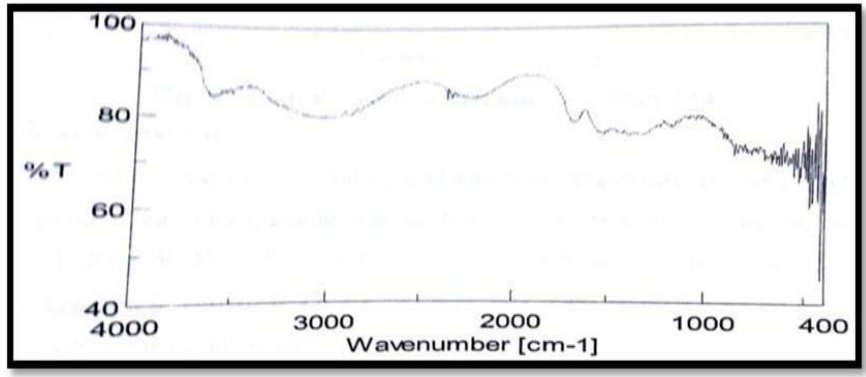

Fig-2: IR Spectrum of Indion 234

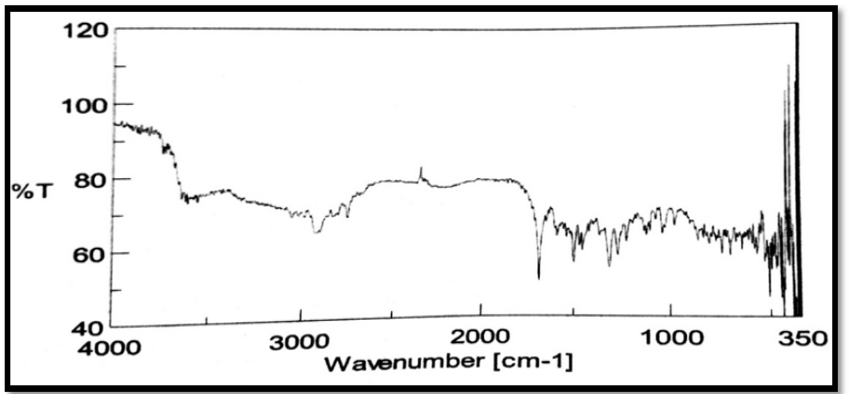

Fig-3: IR Spectrum of drug resinate complex 
FTIR studies indicated that there would be a possibility of chemical modification in the DRC without any changes in basic nucleus of the drug. Taste evalution of ion exchange in healthy human volunteers confirmed that the taste of Ciprofloxacin was successfully masked by ion exchange with (DRC) 1:3 ratios.

\section{Stability study of various formulations}

The accelerated stability study did not show any significant drug loss or changes in the viscosity,
$\mathrm{pH}$, sedimentation ratio and resuspendability of the taste masked suspension of resinate. Suspension of F8 was kept for accelerated study at $40+-2{ }^{\circ} \mathrm{C}$ and $74+-\mathrm{RH}$ for 15 days. The taste masking oral reconstituted suspension evaluated after reconstitution 7 th and 15th day of reconstitution. The samples were observed for any change in physical parameters. It was observed that on any change in colour. It was also noted that suspension was free of any kind of bad odour. Results obtained from the evalution after stability studies are shown in table 8 .

Table-8: Evaluation parameter after stability study of Ciprofloxacin F8

\begin{tabular}{|c|c|c|c|c|c|c|}
\hline \multicolumn{7}{|l|}{ Formulation F8 } \\
\hline & & Day 1 & Day 6 & Day 12 & Day 24 & Day 36 \\
\hline \multirow{2}{*}{ Sedimentation Rate } & $\mathbf{F}$ & 0.1 & 0.1 & 0.1 & 0.1 & 0.1 \\
\hline & $\beta$ & 1 & 0.8 & 0.7 & 0.6 & 0.5 \\
\hline \multicolumn{2}{|l|}{ Viscosity } & $505 \pm 0.14$ & $486 \pm 0.15$ & $440 \pm 0.11$ & $412 \pm 0.12$ & $350 \pm 0.15$ \\
\hline \multicolumn{2}{|l|}{ Colour } & Pale yellow & Pale yellow & Pale yellow & Pale yellow & Pale yellow \\
\hline \multicolumn{2}{|l|}{ Taste } & Palatable & Palatable & Palatable & Palatable & Palatable \\
\hline \multicolumn{2}{|l|}{ pH } & 5.3 & 5.2 & 5.0 & 4.9 & 4.5 \\
\hline \multicolumn{2}{|l|}{ \% Drug Release } & \multicolumn{5}{|l|}{96.21} \\
\hline \multicolumn{2}{|l|}{ \% Drug Content } & \multicolumn{5}{|l|}{97.00} \\
\hline \multicolumn{2}{|l|}{ Assay of Ciproflaxin } & \multicolumn{5}{|l|}{99.97} \\
\hline
\end{tabular}

\section{CONCLUSION}

Thus, from the study we can conclude that the objective to mask the unpleasant taste of the drug i.e. Ciprofloxacin fir paediatric patients is achieved which enhances the palatability of the formulation. Also, by giving the drug the dry syrup form the stability problem of the drug can also be resolved. Hence, the objective of the project work is achieved by the successful development of dry syrup of the drug ciprofloxacin by using weak cation resin Indion 234 for the highly palatable paediatric formulation.

\section{REFRENCES}

1. Pratik P, MR DP, KR DP, NM DP. A review on taste masking pediatric dry syrup. International Journal Of Universal Pharmacy And Bio Sciences. 2013:2319-8141.

2. Kumar Pardeep, Saini Seema, Singh Gurpreet, Benerjee Angsu; Reconstitutable Taste Masked Dry Suspensions (Dry Syrup): An Overview. International Journal Of Recent Advances In Pharmaceutical Research July. 2015; 5(3) 269-276.

3. Bardeskar C, Geeverghese R. Reconstitutable oral suspensions (dry syrups): An overview. World Journal of Pharmaceutical Research. 2014;4(3):462-84.

4. Tripathi A, Parmar D, Patel U, Patel G, Daslaniya D, Bhimani B. Taste masking: a novel approach for bitter and obnoxious drugs. JPSBR. 2011;1(3):36142.

5. Pardeep K. Taste masking potential of bitter drugs: a review. International Journal of Pharma Professional $^{\text {ee }}$ s Research. 2015;6.
6. Tekade BW, Jadhao UT, Thakare VM, Bhortake LR. Formulation and evaluation of diclofenac sodium effervescent tablet. Infrared Spectroscopy. 2014;9(10):11.

7. Thakare VM, Umesh T, Jadhao BW, Chaudhari KP, Piyush N. Development of metoclopramide hydrochloride orodispersibal tablets using taste masking tulsion 339. Journal of Advanced Pharmacy Education \& Research Oct-Dec. 2013;3(4).

8. Keeney $\mathbf{M}$ and Zheng J. Taste masking analysis in formulation development using an electronic tongue. Int. J. Pharm.2006; (310):118-124.

9. Rao NR, Patel T, Gandhi S. Development and evaluation of carbamazepine fast dissolving tablets prepared with a complex by direct compression technique. Asian Journal of Pharmaceutics (AJP): Free full text articles from Asian J Pharm. 2014 Aug 25;3(2).

10. Padalkar AN, Shahi SR, Udavant YK, Salunke RJ, Kuchekar BS. An approach towards taste abatement of Roxithromycin. IJPRD. 2009;1:1-3.

11. Das Saikat, Srikanth L And Saha Suvendu; Taste Masking Of Ciprofloxacin by Ion Exchange Resin; 1(1) Jul-Dec 2010/7-13.

12. Abhijeet YP, Bhoyar PK, Baheti JR, Kardel SM. Formulation and evaluation of stable oral formulation of bitterless ofloxacin complexed with ion exchange resin. World J of Pharm. and Pharm. Sci. 2012;1(1):384-92.

13. Rashmi D. And Sharma R. Formulation and In vitro Evaluation of Taste Masked Orodispersible Tablet of Metoclopramide Hydrochloride Using Indion 204, International Journal of Chem Tech Research. 2010; 2(1):448-451. 
14. Shaikh TJ, Jadhao UT, Deshmukh SB, Deore HV. Formulation and development of orodispersible tablets of lornoxicam by using resinate inclusion complexes.

15. Lachman L, Lieberman HA, Kanig JL. The theory and practice of industrial pharmacy. Philadelphia: Lea \& Febiger; 1976.

16. USP/NF. Physical Tests: Bulk density, Tapped density, Flow properties, Disintegration, Dissolution. 22/17 ed. Rockville MD. United States Pharmacopeial Convention Inc. 1995; 2049-2050.
17. Watson DG. Pharmaceutical AnalysisA Textbook for Pharmacy Students and Pharmaceutical Chemists.

18. Duerst M. Spectroscopic methods of analysis: infrared spectroscopy. Swarbrick J., Boylon JC, Encyclopedia of Pharmaceutical Technology. 2007; 3:3405-18.

19. Skoog DA, Holler FJ, Crouch SR. Principles of instrumental analysis. Cengage learning; 2017 Jan 27. 